\title{
Global, diffuse and direct solar radiation at the surface in the city of Rio de Janeiro: Observational characterization and empirical modeling
}

\author{
Edson P. Marques Filho ${ }^{\text {a, b, }}$, , Amauri P. Oliveira ${ }^{\mathrm{c}}$, Willian A. Vita ${ }^{\mathrm{b}}$,

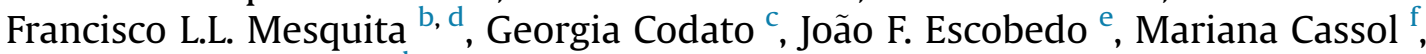 \\ José Ricardo A. França ${ }^{b}$ \\ ${ }^{a}$ Federal University of Bahia, Institute of Physics, Salvador, BA, Brazil \\ ${ }^{\mathrm{b}}$ Federal University of Rio de Janeiro, Institute of Geosciences, Rio de Janeiro, RJ, Brazil \\ c University of SãoPaulo, Institute of Astronomy, Geophysics and Atmospheric Science, São Paulo, SP, Brazil \\ d Brazilian Institute for Space Research, Centre for Weather Forecast and Climate Studies, São José Dos Campos, SP, Brazil \\ e State University of São Paulo, School of Agronomic Sciences, Botucatu, SP, Brazil \\ ${ }^{\mathrm{f}}$ Federal University of Bahia, Institute of Mathematics, Salvador, BA, Brazil
}

\section{A R T I C L E I N F O}

\section{Article history:}

Received 23 March 2015

Received in revised form

10 December 2015

Accepted 8 January 2016

Available online 21 January 2016

\section{Keywords:}

Solar radiation components

Rio de Janeiro

Local climate conditions

Diffuse solar fraction model

\begin{abstract}
A B S T R A C T
The city of Rio de Janeiro and others 18 cities compose the Metropolitan Area of Rio de Janeiro. The main objective of this work is to characterize observationally the diurnal and seasonal evolution of the solar radiation components in the city of Rio de Janeiro. The measurements of global and diffuse solar radiation and standard meteorological variables at the surface have been carried out regularly at the Geoscience Institute of Federal University of Rio de Janeiro since October of 2011. The microclimatic conditions show that the period 2011-2014 was warmer during most of the year and drier in summer and spring in comparison with climate normal. All solar radiation components present a well defined diurnal cycle with maximum at noon. The estimates of global and direct solar radiation indicate a great potential available for solar energy at the surface, particularly in summer. The behavior of the clearness index and diffuse solar radiation fraction is similar in summer and winter. The Angstrom formula represents properly the estimate of the monthly average daily value of global solar radiation. The sigmoid logistic function is statistically more significant in comparison with others correlation models to represent the diffuse fraction as a function clearness index.
\end{abstract}

() 2016 Elsevier Ltd. All rights reserved.

\section{Introduction}

Solar radiation is the main source of energy in most of the surface-atmosphere interactions driving almost all physical, chemical and biological processes in earth's atmospheric and oceanic systems $[1,2]$. The knowledge of global $\left(E_{G}\right)$, diffuse $\left(E_{D F}\right)$ and beam $\left(E_{D R}\right)$ solar radiation components at the surface is crucial to determine areas with potential for solar power generation [3-6], to assess the energy consumption in buildings [7], to subsidize ecophysiological studies [8,9], to estimate the evapotranspiration of crops [10] and to support urban planning [11].

Besides, due to environmental and economical reasons, tropical countries like Brazil will need to use their solar energy potential,

\footnotetext{
* Corresponding author.

E-mail address: edson.marques@ufba.br (E.P. Marques Filho).
}

estimated between 1500 and $2200 \mathrm{~kW} \mathrm{~h} \mathrm{~m}^{-2}$ year $^{-1}$ [12], in order to diversify their energy matrix [13-15]. For instance, Brazil has an installed capacity of $134 \mathrm{GW}$ of power generation, of which solar and wind energy contribute with $5 \%$ of this total [16].

Despite the importance, the knowledge of solar radiation field at the surface is still incipient in Brazil. There are small number of radiometric stations performing high quality measurements of $E_{G}$, $E_{D F}$ and $E_{D R}$, and only few has long-term data sets [3,17-19]. Oliveira et al. [17] were the first authors that establish the seasonal variations of the diurnal evolution of $E_{G}, E_{D F}$ and $E_{D R}$ based on measurements collected at surface of the city of São Paulo. Codato et al. [20] compared the solar radiation field at the surface in the city São Paulo with a rural site located in the city of Botucatu, where a radiometric station is measuring $E_{G}, E_{D F}$ and $E_{D R}$ with high quality since 1994. Even though these two radiometric stations are $250 \mathrm{~km}$ distant apart, they have similar latitude and altitude and the solar 


\begin{tabular}{|c|c|c|c|}
\hline \multicolumn{2}{|c|}{ Nomenclature } & \multirow{2}{*}{$\begin{array}{c}K_{D}^{d} \\
K_{T}\end{array}$} & \multirow{2}{*}{$\begin{array}{l}\text { daily value of diffuse fraction of the solar radiation } \\
\text { (nondimensional) } \\
\text { clearness index (nondimensional) }\end{array}$} \\
\hline$a$ & Angstrom constant & & \\
\hline$E_{G}$ & global solar radiation $\left(\mathrm{Wm}^{-2}\right)$ & $K_{T}^{d}$ & daily value of clearness index (nondimensional) \\
\hline$E_{G}^{h}$ & $\begin{array}{l}\text { hourly value of global solar radiation at the surface (MJ } \\
\mathrm{m}^{-2} \text { hour }^{-1} \text { ) }\end{array}$ & $\begin{array}{l}\text { MDD } \\
q\end{array}$ & $\begin{array}{l}\text { movable detector device } \\
\text { specific humidity }\left(\mathrm{g} \mathrm{kg}^{-1}\right)\end{array}$ \\
\hline$E_{G}^{d}$ & $\begin{array}{l}\text { daily value of global solar radiation at the surface (MJ } \\
\mathrm{m}^{-2} \mathrm{day}^{-1} \text { ) }\end{array}$ & $\begin{array}{l}r \\
R\end{array}$ & $\begin{array}{l}\text { ring width }(\mathrm{cm}) \\
\text { ring-detector distance }(\mathrm{cm})\end{array}$ \\
\hline$E_{D F}$ & diffuse solar radiation $\left(\mathrm{Wm}^{-2}\right)$ & $R H$ & relative humidity (\%) \\
\hline$E_{D F}^{h}$ & $\begin{array}{l}\text { hourly value of diffuse solar radiation at the surface } \\
\left(\mathrm{MJ} \mathrm{m} \mathrm{m}^{-2} \text { hour }^{-1} \text { ) }\right.\end{array}$ & $\begin{array}{l}S \\
S_{\max }\end{array}$ & $\begin{array}{l}\text { monthly average daily value of sunshine hours (hours) } \\
\text { maximum monthly average daily value of sunshine }\end{array}$ \\
\hline$E_{D F}^{d}$ & $\begin{array}{l}\text { daily value of diffuse solar radiation at the surface (MJ } \\
\mathrm{m}^{-2} \text { day }^{-1} \text { ) }\end{array}$ & $T$ & $\begin{array}{l}\text { hours (hours) } \\
\text { air temperature }\left({ }^{\circ} \mathrm{C}\right)\end{array}$ \\
\hline$E_{D R}$ & beam solar radiation $\left(\mathrm{Wm}^{-2}\right)$ & $w$ & hour angle at the sunset (degree) \\
\hline$E_{D R}^{h}$ & $\begin{array}{l}\text { hourly value of beam solar radiation at the surface (MJ } \\
\mathrm{m}^{-2} \text { hour }^{-1} \text { ) }\end{array}$ & $\begin{array}{l}\alpha \\
\delta\end{array}$ & $\begin{array}{l}\text { solar elevation angle (degree) } \\
\text { solar declination angle (degree) }\end{array}$ \\
\hline$E_{D R}^{d}$ & $\begin{array}{l}\text { daily value of beam solar radiation at the surface (MJ } \\
\mathrm{m}^{-2} \mathrm{day}^{-1} \text { ) }\end{array}$ & $\begin{array}{l}\varphi \\
\theta_{z}\end{array}$ & $\begin{array}{l}\text { latitude (degree) } \\
\text { solar zenith angle (degree) }\end{array}$ \\
\hline$E_{T}$ & extraterrestrial solar radiation $\left(\mathrm{Wm}^{-2}\right)$ & $M B E$ & mean bias error \\
\hline$E_{T}^{h}$ & $\begin{array}{l}\text { hourly value of extraterrestrial solar radiation at the } \\
\text { top of atmosphere }\left(\mathrm{MJ} \mathrm{m}^{-2} \text { hour }^{-1}\right)\end{array}$ & $\begin{array}{l}R^{2} \\
R M S E\end{array}$ & $\begin{array}{l}\text { coefficient of determination } \\
\text { root mean square error }\end{array}$ \\
\hline$E_{T}^{d}$ & $\begin{array}{l}\text { daily value of extraterrestrial solar radiation at the top } \\
\text { of atmosphere }\left(\mathrm{MJ} \mathrm{m} \mathrm{m}^{-2} \mathrm{day}^{-1}\right)\end{array}$ & & $\begin{array}{l}\text { t-test } \\
\text { index of agreement }\end{array}$ \\
\hline$F_{C}$ & diffuse correction factor (nondimensional) & $A I C$ & Akaike's information criterion \\
\hline$K_{D}$ & diffuse fraction of the solar radiation (nondimensional) & $\Delta_{i} A I C$ & difference of Akaike's information criterion \\
\hline$K_{D}^{h}$ & $\begin{array}{l}\text { hourly value of diffuse fraction of the solar radiation } \\
\text { (nondimensional) }\end{array}$ & & \\
\hline
\end{tabular}

field at the surface in these both sites shows a similar seasonal variation. More recently, Ferreira et al. [21] characterized observationally the diurnal and seasonal variations of the radiation balance at the surface in the city of São Paulo. They concluded that, in addition to astronomical factors, the seasonal variation of $E_{G}$ depends more on the atmospheric broadband transmissivity and less on the surface effective albedo. Pereira et al. [3] and Martins et al. [22] used $E_{G}$ and $E_{D R}$ measurements collected at surface by SOLAS network to validate the satellite-derived radiative transfer model. They produced maps of $E_{G}, E_{D F}$ and $E_{D R}$ that can be used to estimate the available potential for energy production based on solar radiation for the entire Brazil considering only a set of six surface stations and a short time period of observation.

High quality measurements of $E_{G}, E_{D F}$ and $E_{D R}$ during long periods of time can be used also to develop empirical models. Given $E_{G}$ measurements on a horizontal surface, the $E_{D F}$ component can be obtained through an empirical function that relates diffuse fraction of the solar radiation $\left(K_{D}\right)$ with the clearness index $\left(K_{T}\right)$. This type of empirical model where first proposed by Liu and Jordan [23] to estimate daily values of $E_{D F}$ in terms of $E_{G}$ using a first order polynomial. These empirical models, also known as correlation models, have received considerable attention from the solar radiation community. They are usually expressed in terms of higher order polynomials, exponentials or logistic functions and may include multiple predictions for monthly, daily, hourly and shorter periods of time [24-26]. Erbs et al. [27] developed the correlation model for hourly value, but their results for $E_{G}$ were very sensitive to the presence of clouds. Reindl et al. [28] showed that in addition to $K_{T}$, the inclusion of other variables such as solar elevation, ambient temperature and relative humidity, improved the predict hourly $K_{D}$. Skartveit et al. [29] obtained a better performance for hourly values considering a variability index of $K_{T}$ to represent the influences of clouds in $K_{D}$. These works were developed to data collected in middle latitude regions located in the Northern Hemisphere, which have different characteristics from those observed in Southern Hemisphere [30].

Boland et al. [31] proposed a logistic function to represent $K_{D}$ as a function of $K_{T}$ with superior performance for an Australia location in comparison with the model of [28]. The theoretical framework for the use of the logistic function was presented in Ref. [32]. Oliveira et al. [33] showed that the overall characteristics of the $K_{D}$ correlation model based on $4^{\text {th }}$-order polynomials to the city of Sao Paulo represent the seasonal variations similar to other places with equivalent latitude for hourly, daily and monthly values. Soares et al. [34] used neural network technique to include implicitly the cloud effects in $K_{D}$ using downward atmospheric longwave measurements at the surface. Their results for hourly $K_{D}$ were better than those obtained by Ref. [33] for the same region.

In the search of more universal correlation model for $K_{D}$ including additional predictors to represent the influences of different climate conditions, Ridley et al. [30] proposed the multi predictor model BRL to estimate $E_{D F}$ and $E_{D R}$ components. The daily clearness index, solar altitude, apparent solar time and global radiation persistence are some predictions of the BRL, and the results show a better statistical performance for different regions of the world. According to [35], correlations models performance for short time variations can considerably improve when cloud effects on solar radiation field at the surface are incorporated explicitly. However, estimates of some of these predictions, with high frequency sampling, are not easily available. A review about different correlations models to estimate hourly $E_{D F}$ can be found in Refs. [24-26].

The main objective of this work is to characterize observationally the diurnal and seasonal evolution of $E_{G}, E_{D F}$ and $E_{D R}$ components in the city of Rio de Janeiro. Additionally, a new correlation model, based on fitting of logistic sigmoid function through 
dispersion diagram of $K_{T}$ versus $K_{D}$, to estimate hourly values of $E_{D F}$ at the surface is proposed. Solar radiation measurements used in this study were obtained by the Laboratory of Micrometeorology and Modeling (LabMiM) from 2011 to 2014, at the Geoscience Institute of Federal University of Rio de Janeiro (IGEO-UFRJ). This station is located at Northeast portion of the city of Rio de Janeiro.

The Metropolitan Area of Rio de Janeiro City (MARJ) is the second largest of Brazil with 12.1 million inhabitants, 19 cities and area of $5327 \mathrm{~km}^{2}$ [36]. It is characterized by complex topography and land use. In the MARJ, the urban areas are surrounded by vegetated mountains, Guanabara Bay and Atlantic Ocean shore line [37]. A large industrial park, responsible for $8.0 \%$ of GDP of Brazil, and a fleet of 4.0 million vehicles produce high levels of air pollution concentration [38]. Even though socio-economic importance of the city of Rio de Janeiro, very little is known about its local climate. Lucena et al. [39] used satellite estimates of surface temperature and found an Urban Heat Island intensity of $10^{\circ} \mathrm{C}$ in some areas of MARJ. Recently, Flores et al. [19]. determined the atmospheric turbidity and surface radiative parameters in the MARJ using two parameterized broadband solar irradiance models. Their results showed that Angstrom's turbidity coefficient decreases in summer months due to increase of rainfall. As far as the authors are concerning, there is no other work available in the literature describing solar radiation components at the surface in Rio de Janeiro based on situ measurements.

The description of the site, sensors, database and climatology of the city of Rio de Janeiro will be presented in section 2. In sections 3 and 4, the results and conclusions will be discussed and summarized.

\section{Site, sensors, database and climatology}

This work uses measurements of solar radiation components at the surface in the city of Rio de Janeiro, carried out regularly since
October of 2011 by the Micrometeorology and Modeling Laboratory (LabMiM) on a metallic platform set up at the top of the 2-store building of the Institute of Geosciences (IGEO) in the Federal University of Rio de Janeiro (UFRJ), campus Fundão Island (Fig. 1). The IGEO building is located $10 \mathrm{~m}$ above the mean sea level and the IGEO platform at its top is $12.5 \mathrm{~m}$ above the surface (Fig. 2).

Global solar radiation is measured by a net radiometer model CNR4 (Kipp \& Zonen) and diffuse solar radiation is measured by a pyranometer model PSP (Eppley Lab Inc) coupled to a shadow-ring device, named the movable detector device (MDD), developed by the Laboratory of Solar Radiation from State of São Paulo University [40]. Conventional meteorological variables (temperature, relative humidity, horizontal wind speed, wind direction and precipitation) are measured by a surface weather station model WXT520 (Vaisala).

The measurements are performed with a sampling frequency of $0.2 \mathrm{~Hz}$ and store as 5-min average values by an automatic data acquisition system, composed by a datalogger model CR5000 (Campbell Scientific Inc). From October 2012 to February 2013 measurements were not performed because the platform was upgraded to accommodate other micrometeorological sensors. In the period between October 2011 and December 2014 the sensors were systematically calibrated (each 6 months), using a spectral precision pyranometer model PSP, as a secondary standard [17]. The correction factor of the calibration constants was of the order of $1 \%$.

\subsection{Climate of the city of Rio de Janeiro}

In this work, the main climate features of the city of Rio de Janeiro are assessed based on measurements carried at the IGEO platform (as described above) and three surface weather stations of the Brazilian Weather Service ("Instituto Nacional de Meteorologia") indicated by INMET1, INMET2 and INMET3 (Fig. 1), as described below:

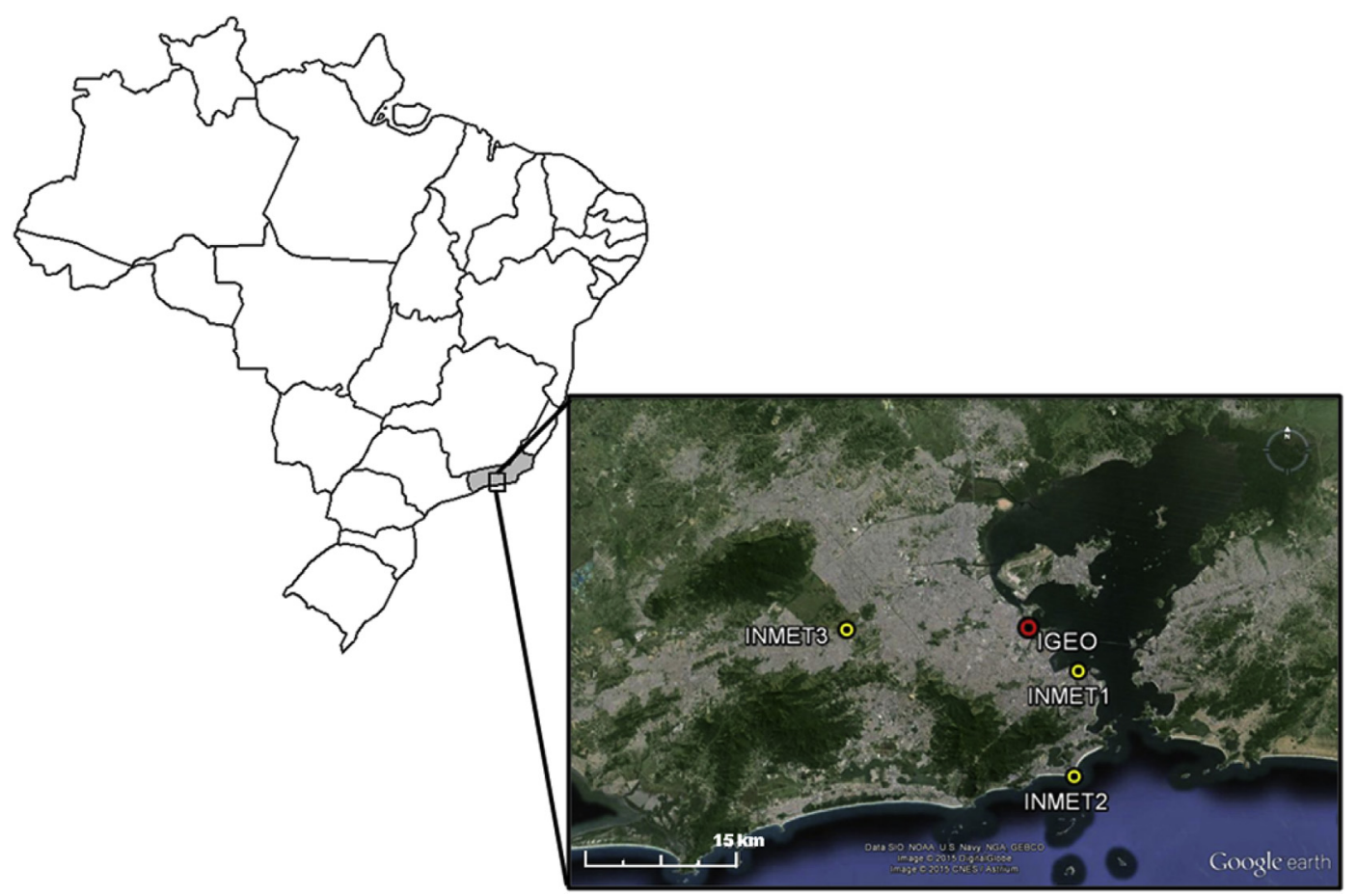

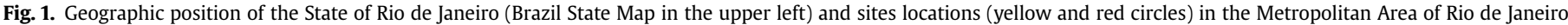

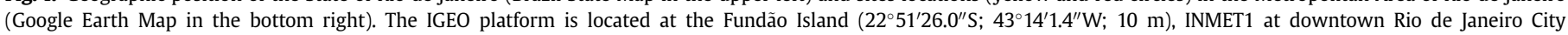

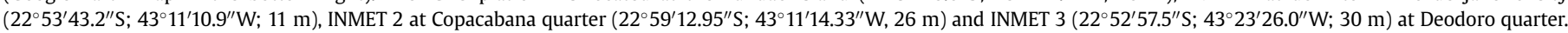


(a)

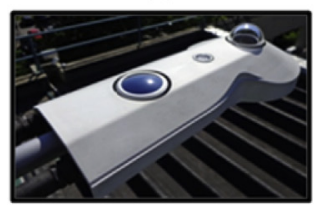

(b)

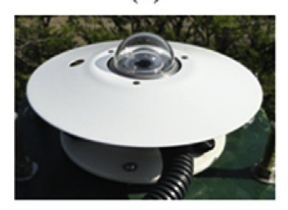

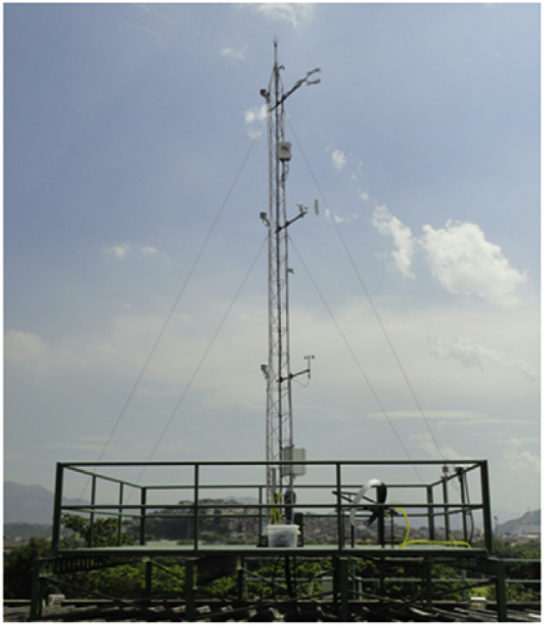

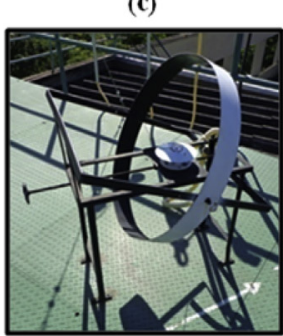

(d)

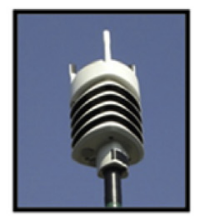

Fig. 2. The instrumental set of the IGEO platform: (a) net radiometer CNR4; (b) pyranometer PSP; (c) shadow-ring device MDD; (d) surface weather station WXT520.

1. Daily values of air temperature $(T)$, relative humidity $(R H)$, accumulate precipitation and cloudiness carried out at the surface weather station located in downtown Rio de Janeiro City from January 1961 to December 1990 (INMET1);

2. 5-minutes average values of $T$ and $R H$ measured from October 2011 to December 2014 and precipitation measured from December 2013 to December 2014 at IGEO platform in the Fundão Island (IGEO);

3. Accumulate daily values of precipitation measured from October 2011 to December 2014 at the surface weather stations located in Copacabana and Deodoro Districts (respectively INMET2 and INMET3).

Surface weather stations INMET1 and INMET2 are situated in urban areas and INMET3 in a suburban area. The altitude of these three surface stations are distributed between 11 and $30 \mathrm{~m}$ above the mean sea level. The IGEO platform is located in a suburban area and the measurements carried out there correspond to $22.5 \mathrm{~m}$ above the mean sea level. Due to the narrow range (10-30 m), the altitude effect on the measurements is not significant and will not be considered in the climate analysis carried out in this work. To reduce the effects of gaps in the time series of precipitation measured at the IGEO platform, observations carried at INMET2 and INMET3 stations were included. This procedure may have introduced some bias in the precipitation characterization, mainly during summer period when precipitation in Rio de Janeiro is mainly due to convective activity and highly variable in space even within the range of distances presented by the stations used in this work ( 15 km, Fig. 1).

According to Köppen-Geiger [41] and considering observations carried out on INMET1, the climate of Rio de Janeiro City is classified as Aw. It alternates a hot and humid summer (December-February) to a mild warm and dry winter (June-August). The criterions that define this climate zone are: mean temperature of the coldest month greater than $18{ }^{\circ} \mathrm{C}$ (Rio de Janeiro value is $21.3^{\circ} \mathrm{C}$ ); the accumulated rainfall of the driest month smaller than $60 \mathrm{~mm} \mathrm{month}^{-1}$ (Rio de Janeiro value is $41.9 \mathrm{~mm} \mathrm{month}^{-1}$ ); and annual accumulated precipitation smaller than $1452.5 \mathrm{~mm}^{-1} \mathrm{year}^{-1}$ (Rio de Janeiro values is $1069.4 \mathrm{~mm}_{\text {year }}{ }^{-1}$ ).

The annual amplitude of the monthly average air temperature $\left(\mathrm{T}_{1961-1990}\right)$ is equal to $5.3^{\circ} \mathrm{C}$, with maximum of $26.6^{\circ} \mathrm{C}$ in February and minimum in July (Fig. 3a). During summer months maximum air temperature above $35{ }^{\circ} \mathrm{C}$ is common, while during winter the minimum air temperature rarely goes below $13{ }^{\circ} \mathrm{C}$. The monthly distribution of relative humidity $\left(\mathrm{RH}_{1961-1990}\right)$ has small variability throughout the year, with monthly average values higher than $75 \%$ (Fig. 3a).

This pattern indicates that the sources of water vapor in this area are available during most of the year in Rio de Janeiro, due to maritime influences of the Atlantic Ocean and Guanabara Bay and
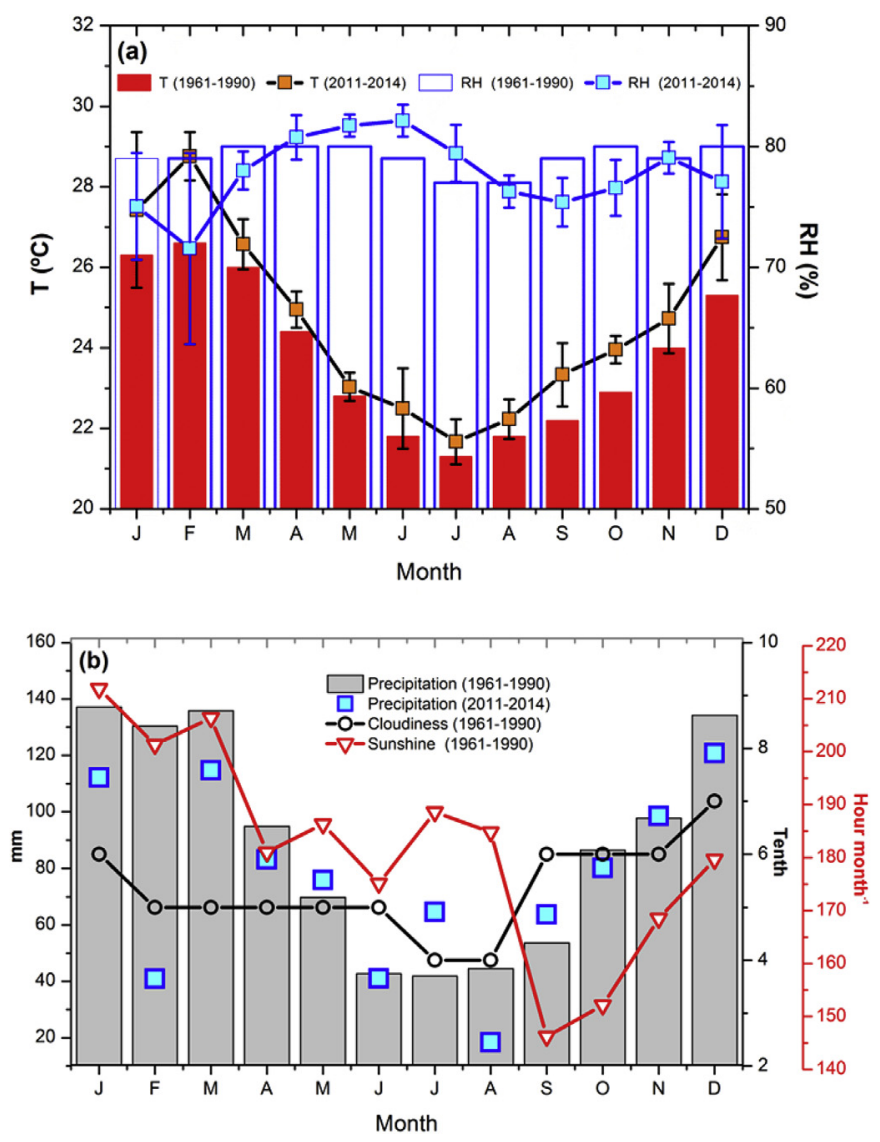

Fig. 3. Seasonal variation of: (a) air temperature and relative humidity; (b) precipitation, cloudiness index and sunshine hours. The variables identified by "(1961-1990)" represent monthly average daily values (INMET 1) and those identified by "(2011-2014)" represent monthly average hourly values (IGEO, INMET 2 and INMET 3). The vertical bars in (a) correspond to standard deviation. 
evapotranspiration from surrounding vegetated areas.

Precipitation in Rio de Janeiro City (Fig. 3b) is influenced by several factors such as sea breeze, topography, cold fronts and especially by atmospheric circulation features associated to the South Atlantic Convergence Zone (SACZ) over this region [42,43]. The accumulate precipitation in the summer is equal to $403 \mathrm{~mm}$ (Dec-Feb), with maximum of $137.1 \mathrm{~mm}$ in January, caused predominantly by the SACZ. In the winter, the accumulate precipitation is $135 \mathrm{~mm}$ (Jun-Aug), with minimum of $41.9 \mathrm{~mm}$ in July, caused by synoptic scale disturbances mainly associated to the passage of cold fronts.

Consistently with the seasonal pattern observed in the precipitation, the cloud cover show a maximum of 7 tenths in December and a minimum of 4 tenths in July and August (Fig. 3b). Despite the higher cloud activity, the monthly accumulate sunshine period is maximum in the summer with $211.9 \mathrm{~h}$ in January, and minimum in the spring with $146.2 \mathrm{~h}$ in September.

Due to the semi permanent South Atlantic Anticyclone circulation [44], the surface mean wind (not show here) is low $\left(1-2 \mathrm{~m}^{-1}\right.$ ) and predominantly from Northeast. This pattern is frequently modified by synoptic scale disturbances (cold fronts) and by sea breeze circulation. The resulting surface circulation is rather complex as consequence of topographic, coast line, body of waters and urban (thermal and mechanical) effects.

To assess the representativeness of microclimate characterized by observations performed at the IGEO platform in the period 2011-2014, the seasonal evolution of T, RH and precipitation are compared with the climate normal estimated from observations carried out during 30 years (1961-1990) at the surface weather station INMET1.

Comparatively to the climate normal, the observations in the IGEO platform indicated that the climate in Rio de Janeiro during the period of 2011 and 2014 was warmer during most of the year and drier during the summer and spring (Fig. 3a). These differences are particularly large during February, when $T_{I G E O}$ is $2{ }^{\circ} \mathrm{C}$ higher and $R H_{\text {IGEO }}$ is $7 \%$ lower than climate normal corresponding values. The monthly average accumulate precipitation in the period 2011-2014 is irregular, especially in summer, that was $30 \%$ less than the climate normal (Fig. 3b).

These discrepancies observed in the previous analysis may have been caused by different and not simultaneous periods of measurements. Besides that, the recent intensification of the rate of increase in the surface air temperature, mostly attributed to climate change $[45,46]$, may have also contributed to these differences, once observations carried out in the IGEO platform covered a period much more recent than in the INMET1. Additionally, differences in land use and marine effects of these two sites may amplify the observed thermal and moisture variations.

An alternative to evaluate the representativeness of measurements collected in IGEO platform is to use the psychrometric diagram to characterize the seasonal climate conditions of this area [47]. As indicated in Fig. 4, the specific humidity $(q)$ and temperature $(T)$ near the surface are well correlated (94\%). The seasonal average values of $q$ are between $11.3 \mathrm{~g} \mathrm{~kg}^{-1}$ in winter and $20.0 \mathrm{~g} \mathrm{~kg}^{-1}$ in summer. The dashed lines in this figure show the values of $q$ as a function of $T$ for different values of $R H$, with the atmospheric pressure equal to $1013 \mathrm{hPa}$. In all seasons, the range of monthly average values of $R H$ are around of $63 \%$ and $88 \%$, consistent with Fig. 3a, which shows $R H$ values within this range.

In general, the climate behavior described by INMET1 and IGEO platform presents similar characteristics, since the cloud of points in the psychrometric diagram for both surface stations (INMET1 indicated by circles and IGEO by triangles) overlap (Fig. 4). The larger scattering of the monthly average values obtained in the IGEO platform, mainly observed in the summer and spring, seems

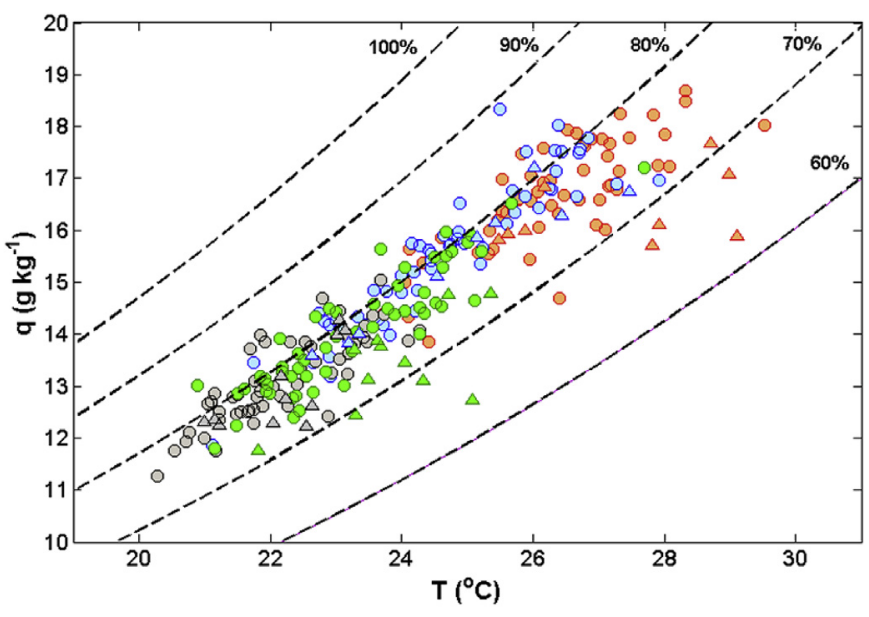

Fig. 4. The psychrometric diagram of monthly average daily values of specific humidity $(q)$ versus monthly average daily values temperature $(T)$. INMET1 and IGEO measurements are indicated by solid circle and triangle, respectively. Summer are indicated by red; Autumn by blue; Winter by gray and Spring by green. The dashed curves are the calculated relations for relative humidity $(R H)$ of $60 \%, 70 \%, 80 \%, 90 \%$, and $100 \%$, with atmospheric pressure equal to $1013 \mathrm{hPa}$.

to be related to climatic variability that are producing warmest and driest summer and spring in the recent years. In the case of the atmospheric water vapor content, the climate characterization using IGEO platform indicated systematic smallest values than INMET1 throughout all seasons.

Therefore, according to the climate analysis carried out here it is possible to infer that the radiation measurements observed between 2011 and 2014 in the IGEO platform are likely to be affected by the fact that city of Rio de Janeiro during this period was warmer and drier when compared to climatological normal. Despite these differences, it will be shown in the section 3 that the mean behavior of $E_{G}$ at the surface follows the estimates based on climate normal values of sunshine hours indicating that it can be considered as representative of the climate of Rio de Janeiro City. The $E_{D F}$ and $E_{D R}$ components of solar radiation measured at IGEO platform seems to be more sensitive to local climate and landuse features.

\subsection{Data base}

In any meteorological measurement system is common the occurrence of problems in recording data. In the case of radiometers, errors in measurements are usually caused by: tilt in the leveling of the sensor; shadowing and reflections from the surrounding objects; accumulation of dust and water on the dome of the sensor [48-50]. Moreover, other factors control the behavior of solar radiation components as cloudiness pattern, aerosol optical depth, surface albedo, cloud type, etc. [51,52], making difficult to obtain universal models [26,53].

To perform measurements of $E_{D F}$ with MDD is necessary to compensate the blocking effect caused by the shadow band. This can be accomplished by considering the solar radiation field at the surface isotropic and multiplying the observed values by the factor $F_{C}>1$. The expression used to estimate $F_{C}$ was proposed by Ref. [40] and is given by:

$$
F_{C}=\left\{1-\left[\frac{2 r}{\pi R}\right] \cos \delta\left[\frac{\cos (\varphi+\delta)}{\cos \varphi}\right]^{2} \times\left[\int_{0}^{w} \cos \left(\theta_{Z}\right) d w\right]\right\}^{-1}
$$

where $r$ is the ring width, $R$ is the ring-detector distance, $\delta$ is the 
solar declination angle, $\varphi$ is the local latitude, $\theta_{z}$ is the zenithal angle and $w$ is the hour angle at the sunset. The values of $r$ and $R$ of the device used in IGEO platform are equal to $10 \mathrm{~cm}$ and $40 \mathrm{~cm}$, respectively, and the $F_{C}$ varies from a maximum of 1.236 in January, when the shadow band is nearest to the pyranometer, to a minimum of 1.053 in June, when this distance is largest and the blocking is a minimum.

To remove the problems, the dataset was subjected to a strict visual quality control in order to identify inconsistencies and spikes generated by electronic problems of data acquisition system. Additionally, the methodology proposed by Younes et al. [50] and Journée et al. [54] was applied to the time series. Data was classified as valid when the solar elevation angle $(\alpha)$ is greater than $2^{\circ}$ and the ratios:

$$
\begin{gathered}
E_{G} / E_{T}<1 \\
E_{D F} / E_{T}<0.8 \\
E_{D F} / E_{G}<1.1
\end{gathered}
$$

where $E_{T}$ is the extraterrestrial solar radiation on a horizontal surface. The component $E_{T}$ is estimated analytically [55], considering the solar constant equal to $1366 \mathrm{~W} \mathrm{~m}^{-2}$ [56].

Approximately $2.5 \%$ of the dataset was removed based on the criteria of $\alpha>2^{\circ}$. It corresponds to measurements carried out during sunrise and sunset periods when $\theta_{z}$ is high, mainly during winter and spring. Criteria $E_{G} / E_{T}<1$ removed $12.0 \%$ of the dataset and it was not observed dependence on $\theta_{z}$ and season. The most restrictive criteria is $E_{D F} / E_{T}<0.8$ that removed $31.7 \%$ of the dataset mainly during the summer (rainy months). This criteria also removed data corresponding to the periods when $E_{D F}$ measurements were not valid due to problems in the shadow-ring settings, carried out manually in the case of the MDD device. The last criteria $E_{D F} / E_{G}<1.1$ removed only $1 \%$ of the dataset and showed no dependence on astronomical and seasonal factors.

After quality control of data, 865 days were selected to characterize the seasonal variation of solar radiation over the area, covering $73 \%$ of the whole period of observations (Fig. 5). Finally, the statistical analysis were performed in the measurements of $E_{G}, E_{D F}$ and other meteorological variables.

Two variables are used in this work to analyze the radiometric properties of the atmosphere and to develop the correlation model: clearness index $\left(K_{T}=E_{G} / E_{T}\right)$; and diffuse fraction $\left(K_{D}=E_{D F} / E_{G}\right)[23]$. Under clear sky conditions, a large fraction of extraterrestrial radiation reaches the surface so that $E_{G} \rightarrow E_{T}$ and $K_{T} \rightarrow 1$ while $E_{D F} \rightarrow 0$ and $K_{D} \rightarrow 0$. On the other hand, under cloudy conditions $E_{G} \rightarrow E_{D F}$ so that $K_{T} \rightarrow 0$ while $K_{D} \rightarrow 1$. The main advantage of using $K_{T}$ and $K_{D}$ is to

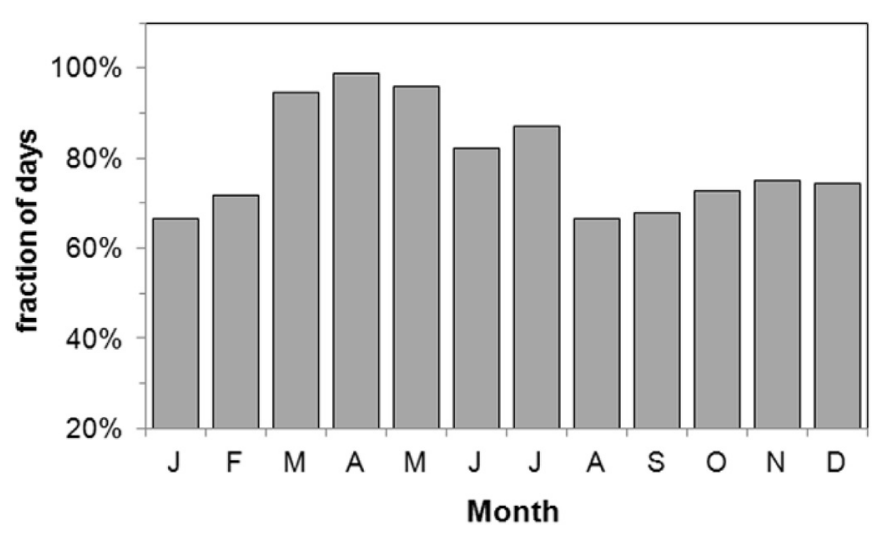

Fig. 5. Monthly average fraction days with valid observations between October of 2011 and December of 2014

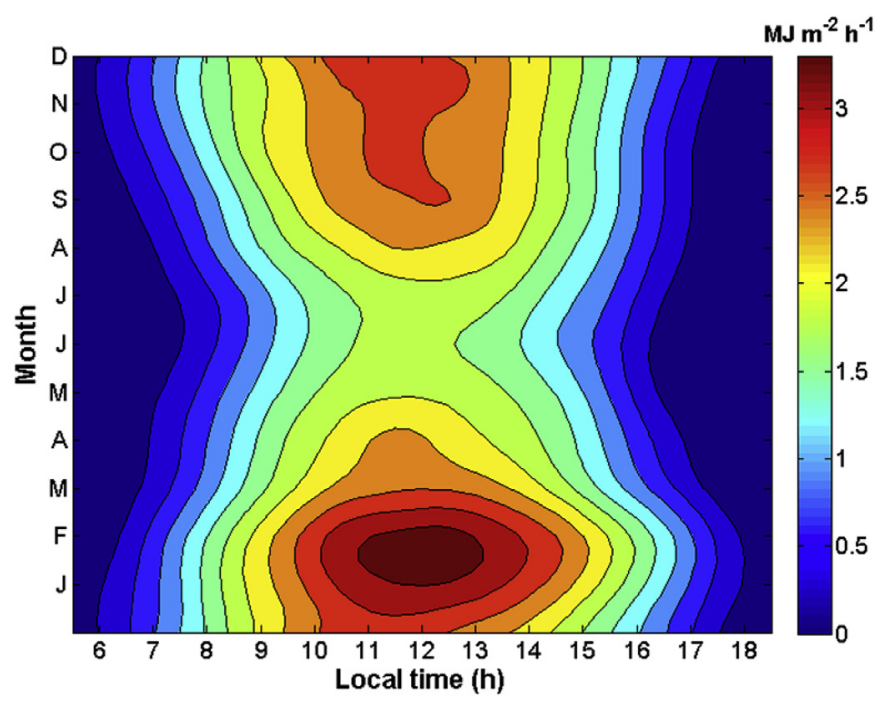

Fig. 6. Monthly average $E_{G}^{h}$ for the city of Rio de Janeiro.

remove the astronomical dependency but retaining relevant information about how the clouds, moisture content and aerosol loads affect radiometric properties yielding a more universal description of these properties and allowing their application in regions with similar climate [31].

The solar radiation measurements may be affected by operational errors as shadow-ring misalignment, incorrect sensor leveling, shading and spurious reflection caused by building and other structures, horizontal variation of surface albedo induced by complex topography and land use, uneven distribution of clouds caused by topography, etc. [2,57]. Even with pyranometers regularly calibrated and with quality control procedure described above the systematic and random, errors about $\pm 10 \%$ can occur [58]. These factors affecting the quality of radiometric measurements may be aggravated in the case of observations carried out in sites located in urban or suburban complex areas.

To take into consideration all these effects, a correction was applied for the hourly values of $E_{G}$ and $E_{D F}$ by adjusting these observations to the expected behavior in a Liu-Jordan diagram. Comparatively, observations in IGEO platform displayed the largest discrepancy with respect to the typical Liu-Jordan diagram curve when $K_{T} \rightarrow 0$. This spurious effect is possibly generated by multiple reflections caused by obstacles, since the $E_{D F}$ measurements are collected in a metallic platform located over the 2-store building roof (Fig. 2) with characteristics that can modify the radiation field [2]. To minimize these discrepancies, a linear adjustment with amplitude maxima equal to $12 \%$ for $K_{T} \rightarrow 0$ and zero to $K_{T} \rightarrow 1$ was applied in all hourly values of $E_{D F}$ in trimmed dataset. The resulting Liu-Jordan diagram for Rio de Janeiro will be presented in Section 3.3..

\section{Results and discussion}

In this section, all time integrated values of solar radiation components at the surface are indicated by $E_{x}^{Y}$ and expressed in megajoules per unit of area ( $\mathrm{MJ} \mathrm{m}^{-2}$ time interval $^{-1}$ ). The subscript $\mathrm{X}$ are $T, G, D F$ and $D R$ indicating extraterrestrial, global, diffuse and direct solar radiation, respectively. The $E_{D R}$ is estimated as the difference between $E_{G}$ and $E_{D F}$ components observed at the surface. The superscript $Y$ are $h$ and $d$ indicating time interval of integration of $1 \mathrm{~h}$ and one day, respectively. 


\subsection{Seasonal variation of hourly values}

The seasonal variation of diurnal evolution of $E_{G}^{h}$ (Fig. 6) is obtained from the matrix of monthly average $E_{G}^{h}$ and interpolated by cubic spline method [59]. The monthly average $E_{G}^{h}$ follows the behavior of $E_{T}^{h}$, with a maximum of $3.4 \mathrm{MJ} \mathrm{m}^{-2}$ hour $^{-1}$ in the summer (February) and minimum of $1.8 \mathrm{MJ} \mathrm{m}^{-2}$ hour $^{-1}$ in the winter (June), both at noon. The longest and shortest days of sunshine hours occur in December (13.4 h) and June (10.6 h), respectively.

The highest $E_{G}^{h}$ in February is associated to a combination of astronomical factor and the cloudiness pattern observed during 2011-2014 in the city of Rio de Janeiro. In this period, the monthly average precipitation in February is $40.9 \mathrm{~mm}$, far below the climate normal of $130.4 \mathrm{~mm}$ (Fig. 3b), and $K_{T}^{d}$ presents a local maximum of 0.64 (not showed). Therefore, in this case the combination of these factors indicates that the reduction in the precipitation seems to be associated to the reduction in the cloud cover that favored large values of $E_{G}^{h}$.

The diurnal evolution of monthly average $E_{T}^{h}, E_{G}^{h}, E_{D F}^{h}$ and $E_{D R}^{h}$ during summer and winter months is shown in Fig. 7 and Table 1. All solar radiation components show a well defined diurnal cycle with maximum at noon. The small values of the standard error of the mean (vertical bars) indicate that monthly average values of solar radiation components at the surface in the IGEO platform are representative of the mean conditions observed in Rio de Janeiro. The amplitude of diurnal cycles of $E_{T}^{h}\left(5.01 \pm 0.01 \mathrm{MJ} \mathrm{m}^{-2}\right.$ hour ${ }^{-1}$ ) and $E_{G}^{h}\left(3.15 \pm 0.12 \mathrm{MJ} \mathrm{m}^{-2}\right.$ hour $^{-1}$ ) in summer (Fig. 7a) are respectively $44 \%$ and $53 \%$ higher in comparison with the values observed in winter (Fig. 7b). Similar variation is observed for diurnal cycles of $E_{D F}^{h}\left(0.84 \pm 0.09 \mathrm{MJ} \mathrm{m}^{-2}\right.$ hour $\left.^{-1}\right)$ and $E_{D R}^{h}$ $\left(2.31 \pm 0.18 \mathrm{MJ} \mathrm{m}^{-2}\right.$ hour $\left.^{-1}\right)$ with reductions in winter of the order of $35 \%$.

The analysis of $K_{T}$ and $K_{D}$ allows a better understanding of the diurnal cycle of the atmospheric transmittance, since the dependence of $E_{T}, E_{G}$ and $E_{D F}$ on the astronomical factors are removed. Thus, $K_{T}$ and $K_{D}$ become an important indicator of the processes of scattering and absorption carried out by clouds and aerosols load in the atmosphere.

The diurnal evolution of $K_{T}^{h}$ shows a maximum around 11 LT in summer (Fig. 8a) and 12 LT in winter (Fig. 8b). Minimum values of $K_{T}^{h}$ occur in the hours near to sunrise and sunset, except in the winter where the high value of $K_{T}^{h}$ at 7 LT may be caused by surface reflections due to lower values of $\alpha$ in this season. The $K_{D}^{h}$ has an inverse behavior in comparison with $K_{T}^{h}$. The amplitude of
Table 1

Seasonally average hourly values of solar radiation components, clearness index and diffuse fraction observed in Rio de Janeiro. The hourly values correspond to noontime.

\begin{tabular}{lll}
\hline Components & Summer $\left(\mathrm{MJ} \mathrm{m}^{-2} \mathrm{~h}^{-1}\right)$ & Winter $\left(\mathrm{MJ} \mathrm{m}^{-2} \mathrm{~h}^{-1}\right)$ \\
\hline$E_{T}$ & $5.01 \pm 0.01$ & $3.47 \pm 0.03$ \\
$E_{G}$ & $3.15 \pm 0.12$ & $2.06 \pm 0.11$ \\
$E_{D F}$ & $0.84 \pm 0.09$ & $0.53 \pm 0.04$ \\
$E_{D R}$ & $2.31 \pm 0.18$ & $1.52 \pm 0.29$ \\
Fractions & Summer & Winter \\
$K_{T}$ & $0.60 \pm 0.06$ & $0.59 \pm 0.03$ \\
$K_{D}$ & $0.29 \pm 0.09$ & $0.27 \pm 0.04$ \\
\hline
\end{tabular}

seasonally average values $K_{T}^{h}$ and $K_{D}^{h}$ for the Rio de Janeiro are of the same order of magnitude in both seasons (Table 1 ). The average values of $K_{T}^{h}$ and $K_{D}^{h}$ between 10 LT and 13 LT are 0.59 and 0.28 , respectively.

\subsection{Seasonal variation of daily values}

The seasonal variation of monthly average daily values of the solar radiation components at the surface in Rio de Janeiro is presented in the Fig. 9 and Table 2.

The highest values of $E_{G}^{d}$ and $E_{D R}^{d}$ are observed in the summer.

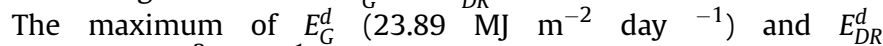
$\left(18.51 \mathrm{MJ} \mathrm{m}^{-2}\right.$ day ${ }^{-1}$ ) in February are related to climate exceptionally warm and dry in this month in the observed period 2011-2014 (Figs. 3 and 4). The minimum of $E_{G}^{d}\left(10.78 \mathrm{MJ} \mathrm{m}^{-2}\right.$ day $\left.{ }^{-1}\right)$ and $E_{D R}^{d}\left(6.83 \mathrm{MJ} \mathrm{m}^{-2}\right.$ day $\left.^{-1}\right)$ in June agrees with the decreasing of $E_{T}^{d}\left(22.65 \mathrm{MJ} \mathrm{m}^{-2}\right.$ day $\left.{ }^{-1}\right)$. In comparison with winter, the amplitude of $E_{G}^{d}\left(22.00 \pm 2.73 \mathrm{MJ} \mathrm{m}^{-2}\right.$ day $\left.{ }^{-1}\right)$ and $E_{D R}^{d}$ $\left(15.75 \pm 3.86 \mathrm{MJ} \mathrm{m}^{-2}\right.$ day $\left.^{-1}\right)$ in the summer are $75 \%$ highest.

The seasonal evolution of $E_{D F}^{d}$ is strongly related to the cloudiness pattern in Rio de Janeiro, decreasing to a minimum (3.74 $\mathrm{MJ} \mathrm{m}^{-2}$ day ${ }^{-1}$ ) in july and increasing to a maximum $\left(7.34 \mathrm{MJ} \mathrm{m}^{-2}\right.$ day $\left.^{-1}\right)$ in december, transition month between spring and summer, respectively. In general, the winter average value of $E_{D F}^{d}\left(3.87 \pm 0.13 \mathrm{MJ} \mathrm{m}^{-2}\right.$ day $\left.^{-1}\right)$ is $38 \%$ smaller than that observed in the summer.

The observed summer and winter average values of $E_{G}^{d}$ (Table 2) agree with the values estimate from maps proposed by Ref. [3], respectively $20.8 \pm 0.6 \mathrm{MJm}^{-2}$ day $^{-1}$ and $13.2 \pm 0.6 \mathrm{~m}^{-2}$ day ${ }^{-1}$. However, the seasonal values of $E_{D F}^{d}$ suggested by Ref. [3] in the summer $\left(8.2 \pm 0.3 \mathrm{MJm}^{-2} \mathrm{day}^{-1}\right)$ and winter $\left(4.4 \pm 0.3 \mathrm{MJm}^{-2}\right.$ day $\left.^{-1}\right)$ are greater than the observed. These
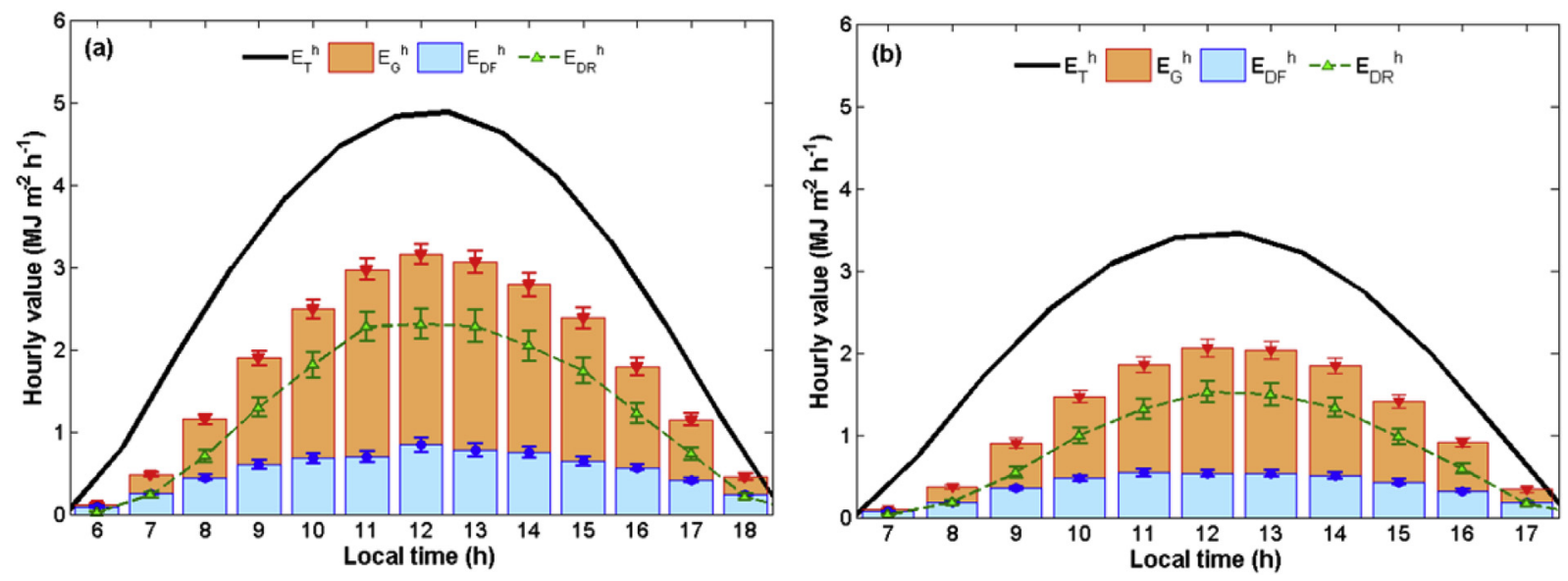

Fig. 7. Diurnal variation of $E_{T}^{h}, E_{G}^{h}, E_{D F}^{h}$ and $E_{D R}^{h}$, for the: (a) summer; (b) winter. The standard error of the mean bars correspond to $95 \%$ confidence interval. 

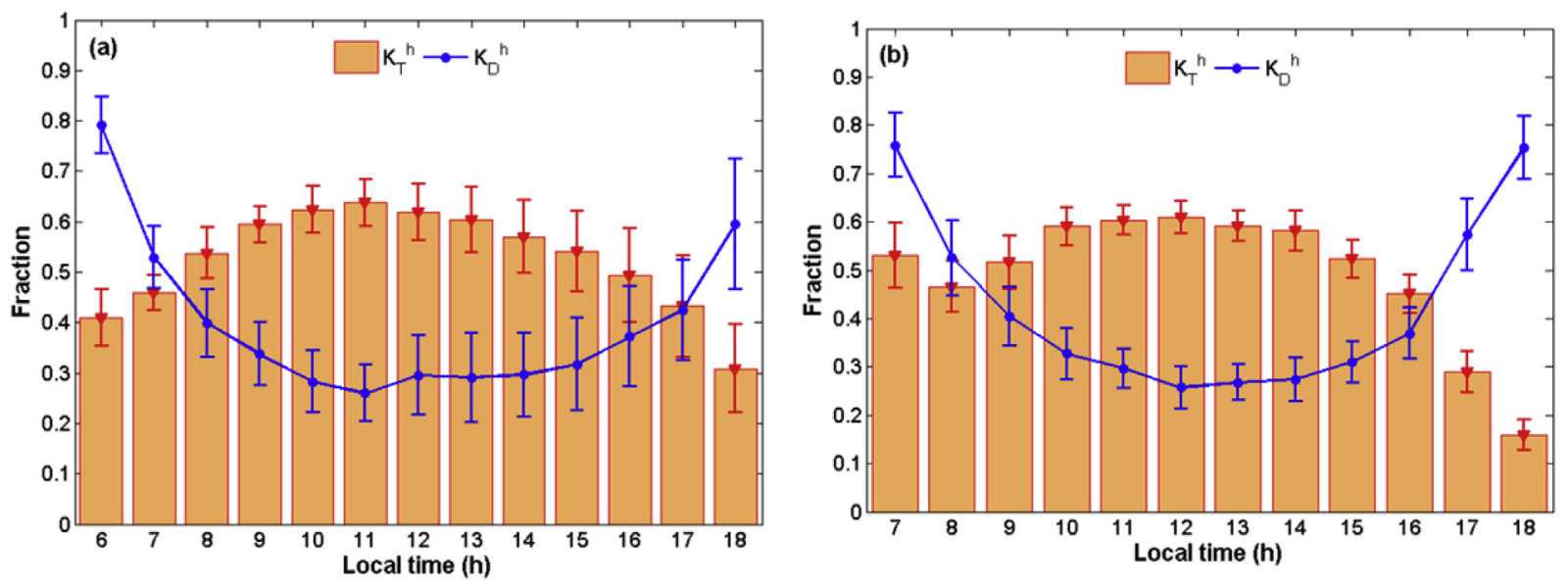

Fig. 8. Diurnal evolution of $K_{T}^{h}$ and $K_{D}^{h}$ in the: (a) summer; (a) winter. The error bars correspond to $95 \%$ confidence interval.

differences for $E_{D F}$ may be related to several factors. First of all, the maps proposed by Ref. [3] are based on a combination of satellite estimates and modeling that was not validated with in situ observations of $E_{D F}$ for the city of Rio de Janeiro. Secondly, considering that the measurements performed in IGEO platform reflect local microclimate and land use, the disagreement may indicated that there are spatial variations in the solar radiation field in the city of Rio de Janeiro that are not identified in the maps of [3]. Regarding the temporal representativeness, both studies used observations collected in different time intervals. The surface measurements used here were collected in a drier period compared to climatological normal (Fig. 3), i.e. with less $E_{D F}$.

To assess the temporal and spatial representativeness of the $E_{G}$ in the period 2011-2014, the Angstrom formula is used to estimate $E_{G}^{d}[60]$ :

$\frac{E_{G}^{d}}{E_{T}^{d}}=a+b \frac{S}{S_{\max }}$

where $S$ and $S_{\max }$ are monthly average and maximum monthly average daily values of sunshine hours, respectively. The values of $a=0.18$ and $b=0.615$ are valid for latitudes $40^{\circ} S-40^{\circ} N$ [17].

Except for February, the modeled values (obtained from observations of sun shining hours in INMET1) agree with the observations of $E_{G}^{d}$ (carried out in IGEO platform) (Fig. 9), with correlation coefficient equal to 93.6\%. This indicates that $E_{G}$ measurements collected in IGEO platform are representative of the climatic conditions observed in the city of Rio de Janeiro, despite the existing discrepancies in the climate characterization based on $T, R H$ and precipitation measurements of both stations.

Table 2

Seasonal average hourly and daily values of solar radiation components, clearness index and diffuse fraction observed in Rio de Janeiro.

\begin{tabular}{lll}
\hline Components & Summer $\left(\mathrm{MJ} \mathrm{m}^{-2}\right.$ day $\left.^{-1}\right)$ & Winter $\left(\mathrm{MJ} \mathrm{m}^{-2}\right.$ day $\left.^{-1}\right)$ \\
\hline$E_{T}$ & $41.69 \pm 1.95$ & $24.83 \pm 3.14$ \\
$E_{G}$ & $22.00 \pm 2.73$ & $12.63 \pm 2.52$ \\
$E_{D F}$ & $6.25 \pm 1.14$ & $3.87 \pm 0.13$ \\
$E_{D R}$ & $15.75 \pm 3.86$ & $8.76 \pm 2.51$ \\
& Summer & Winter \\
$K_{T}$ & $0.56 \pm 0.06$ & $0.55 \pm 0.03$ \\
$K_{D}$ & $0.32 \pm 0.07$ & $0.31 \pm 0.04$ \\
\hline
\end{tabular}

\subsection{Correlation model}

In this work, the sigmoid logistic function is used to represent the relationship between $K_{D}^{h}$ and $K_{T}^{h}$ because comparatively to other logistic functions [30-32] it reproduces best the behavior of $K_{D}^{h}$ for all values $K_{T}^{h}$ and especially when $K_{T}^{h} \rightarrow 1$. To construct the regression model, the dataset is divided in two parts, in chronological order: (a) between the years 2011-2013 to build the regression model; and (b) 2014 to perform the statistical tests.

To carry out a performance analysis of regression models, five statistical parameters are used: i) square linear correlation coefficient $\left(\mathrm{R}^{2}\right)$; ii) mean bias error (MBE); iii) root mean square error (RMSE); iv) index of agreement (d); and v) t-test.

Fig. 10 shows the scatter plot of $K_{D}^{\mathrm{h}}$ versus $\mathrm{K}_{\mathrm{T}}^{\mathrm{h}}$ (Liu-Jordan Diagram). The sigmoid function proposed in this work is compared with models developed for regions locate in South Hemisphere $[32,33]$ or influenced by marine factor [24] (Table 3), as the city of Rio de Janeiro.

It is possible to observe that the sigmoid function agrees better with the behavior of the block averaged experimental curve in comparison with the other correlation models [24,32,33]. It is important to emphasize that the logistic function [32] adjusted to

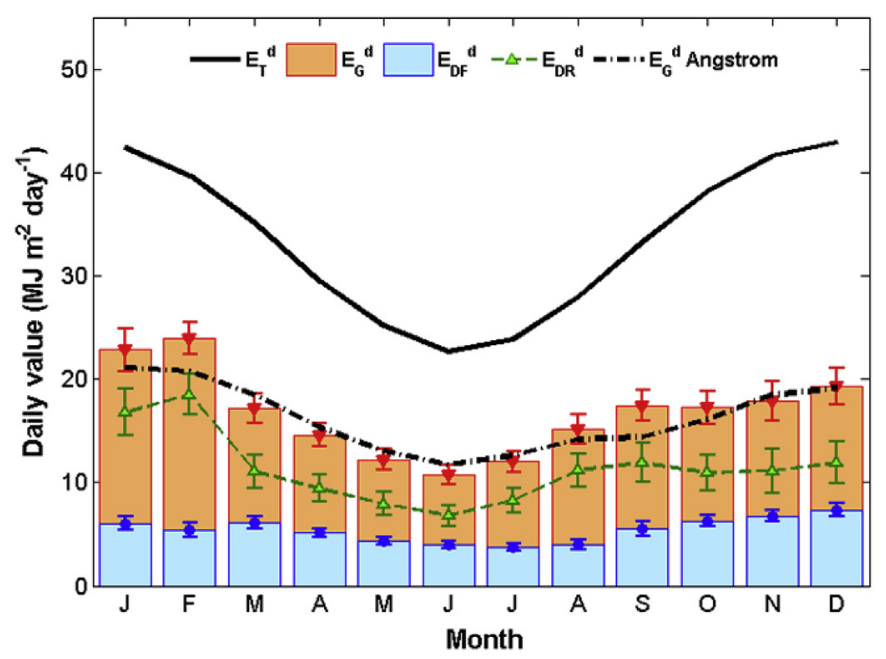

Fig. 9. Annual variation of $E_{T}, E_{G}, E_{D F}$ and $E_{D R}$, in the: (a) monthly average hourly; (b) monthly average daily. The point black dashed line in (b) represent the Angstrom formula (Eq. (4)). The errors bars correspond to $95 \%$ confidence interval. 


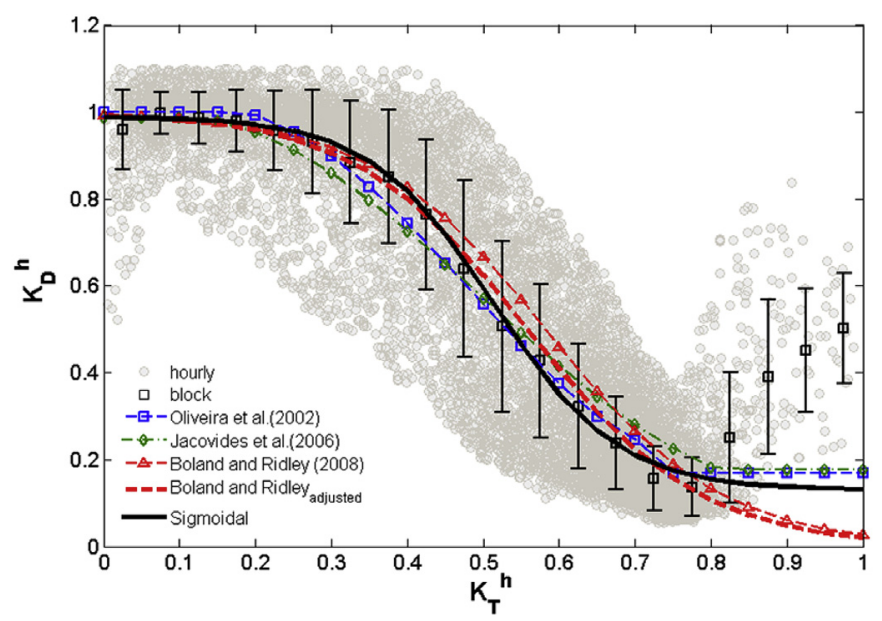

Fig. 10. $K_{T}^{h}$ versus $K_{D}^{h}$ for the city of Rio de Janeiro. The solid squares represent the block average and vertical lines the standard deviation. The solid and dashed lines represent the correlation models developed by different authors.

Rio de Janeiro dataset improved the statistical performance of this model but the sigmoid function continues to present the best results. The adjustment was not performed for polynomial functions because climate conditions of Rio de Janeiro did not diverge much from those of São Paulo.

The statistical parameters in Table 3 indicate that all models present coefficient of determination higher than $85 \%$. The proposed sigmoid function fitting had the better statistical performance followed by Ref. [32] adjusted and [33], with lower MBE and RMSE, and $\mathrm{d}$ near to 1 . However, all correlation models predictions are statistically significant at the confidence level equal to $95 \%$. The agreement between the present fitting with [33] probably occurs due to the geographic similarities of both experimental sites (similar latitude and land use suburban).

The Akaike's Information Criterion (AIC) is a method to evaluate the performance of different models and is defined as:

$A I C=\ln \left(\frac{\sum\left(y_{i}-\mu_{i}\right)^{2}}{n}\right)+\frac{2 k}{n}$

where $y_{i}$ is the observed data, $\mu_{i}$ is the modeled data, $n$ is the sample size and $k$ is the number of parameters of the model [61]. The second term on the right side of this equation represents a penalty due to the number of parameters existing in the model. However, to
Table 4

Statistical performance of the sigmoid model in comparison with the other models to the city of Rio de Janeiro.

\begin{tabular}{llll}
\hline Models & Number of parameters & AIC & $\Delta_{i}$ AIC \\
\hline Sigmoid & 4 & -4.115 & 0.000 \\
Oliveira et al. [33] & 7 & -4.057 & 0.059 \\
Jacovides et al. [24] & 6 & -3.949 & 0.166 \\
Boland and Ridley [32] & 2 & -3.895 & 0.221 \\
Boland and Ridley Adjusted & 2 & -4.069 & 0.047 \\
\hline
\end{tabular}

evaluate the performance of a model comparatively to other ones, it is necessary to calculate the difference of AIC:

$\Delta_{i} A I C=A I C_{i}-A I C_{\min }$

where $A I C_{i}$ is the $A I C$ value for the model $i$, and $A I C_{\min }$ is the minimum AIC value calculated for different models. This transformation forces the best model to have $\Delta_{i} A I C=0$, while the other models have positive values [62].

The AIC statistical method shows that the sigmoid function for the city of Rio de Janeiro is the best model (Table 4). However, all correlation models are statistically relevant $\left(\Delta_{i} A I C<2\right)[62]$ and can be applied to reproduce the behavior of $K_{D}^{h}$ as a function of $K_{T}^{h}$. Although the logistic function proposed by Ref. [32] considers only two parameters, the curve fitting adjusted to Rio de Janeiro dataset does not present the best performance. This occurs probably because the curve of points $\left(K_{D}^{h}, K_{T}^{h}\right)$ simulated by Ref. [32] is the most divergent from the mean values (Fig. 10).

\section{Conclusions}

The main objective of this work is to characterize observationally the diurnal and seasonal evolution of $E_{G}, E_{D F}$ and $E_{D R}$ components in the city of Rio de Janeiro. Additionally, it is proposed a new correlation model to estimate $E_{D F}^{h}$ from $E_{G}^{h}$ based on a sigmoid logistic function to represent the observed block average curve in the Liu-Jordan $K_{T}^{h}-K_{D}^{h}$ diagram for the city of Rio de Janeiro.

These goals were accomplished by using 5-min average values of $E_{G}$ and $E_{D F}$ collected from 2011 to 2014 at the platform located at the top of 2-store building of the Geosciences Institute in the campus of the Federal University of Rio de Janeiro, Fundão Island, characterized by a suburban landuse. Considering the fact that observations were carried in a non-conventional radiometric platform, several procedures were used to unsure data set quality that includes adjusting hourly values of $E_{G}$ and $E_{D F}$ to expected behavior of Liu-Jordan diagram curve.

Table 3

Statistical performance of the models for calculating the hourly averaged diffuse fraction. $K_{D}^{h}$

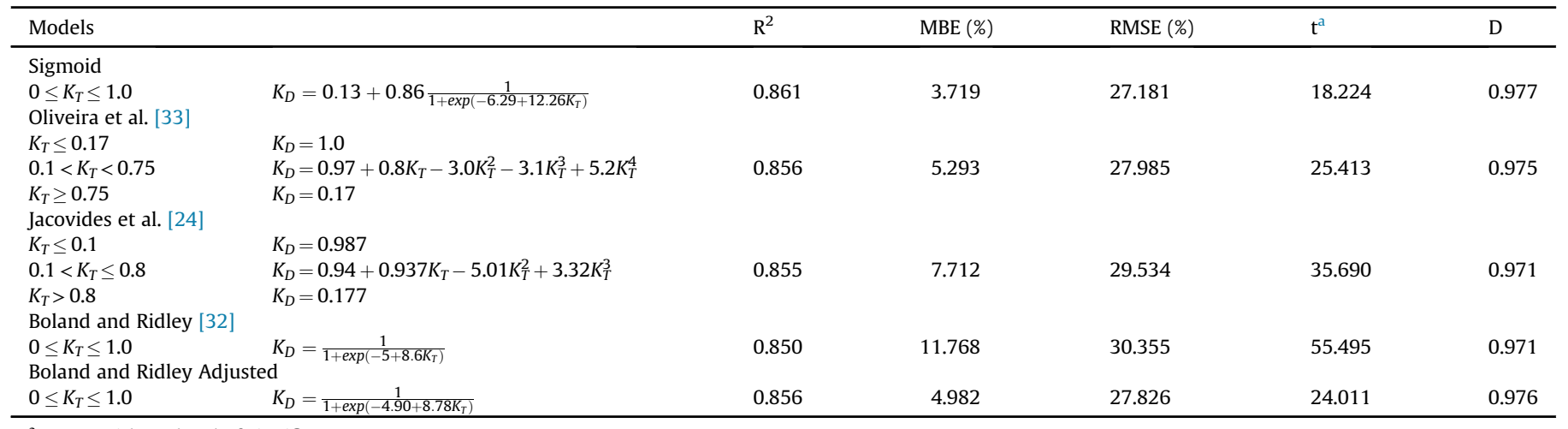

${ }^{\mathrm{a}} \mathrm{t}$ test with $5 \%$ level of significance. 
In the summer, the diurnal evolution of seasonally average $E_{C}^{h}$ and $E_{D F}^{h}$ indicates a maximum amplitude of $3.15 \pm 0.12$ $\mathrm{MJm}^{-2}$ hour $^{-1}$ and $0.84 \pm 0.09 \mathrm{MJm}^{-2}$ hour ${ }^{-1}$ respectively. In the winter, the amplitude of the seasonally average $E_{G}^{h}$ and $E_{D F}^{h}$ are $35 \%$ lowest.

The amplitude of seasonally average values of $K_{T}^{h}$ and $K_{D}^{h}$ for the Rio de Janeiro has the same order of magnitude in both seasons, with maximum $K_{T}^{h}$ of 0.60 and minimum $K_{D}^{h}$ of 0.26 .

The seasonal estimates of $E_{G}^{d}$ agree with the values of the seasonal maps obtained by Ref. [3] through satellite-model techniques. However, the $E_{D F}^{d}$ values observed in Rio de Janeiro were lower than those presented in the maps.

The predictions using Angstrom expression reproduced the annual variation of $E_{G}^{d}$, with correlation coefficient equal to $93.6 \%$. This result ensures the spatial and temporal representativeness of the $E_{G}$ measured in the IGEO platform.

A new correlation model, based on sigmoid function, reproduces adequately the behavior of $K_{D}^{h}$ as a function of $K_{T}^{h}$, and its statistical performance is better than the others correlation models developed for different regions:

$K_{D}=0.13+0.86 \frac{1}{1+\exp \left(-6.29+12.26 K_{T}\right)}, \quad 0 \leq K_{T} \leq 1.0$

In the future, this new model will be tested in $E_{D F}$ measurements collected in other regions of Brazil, for example São Paulo and Botucatu.

\section{Acknowledgements}

The authors are grateful to the Fundação de Amparo a Pesquisa do Estado do Rio de Janeiro (FAPERJ Procs. $n^{\circ}$ E26/111.620/2011 and E-26/103.407/2012), the Fundação de Amparo a Pesquisa do Estado de São Paulo (FAPESP Proc. $n^{\circ}$ 2011/50178-5) and the Conselho Nacional de Desenvolvimento Científico e Tecnológico (CNPq Procs. $\mathrm{n}^{\circ} 308597 / 2012-5$, n ${ }^{\circ} 309079 / 2013-6$ and $\left.n^{\circ} 462734 / 2014-5\right)$ for the financial support. Acknowledgement to the Instituto Nacional de Meteorologia (INMET) by the surface meteorological data. Thanks also to Prof. Hugo A. Karam of the Federal University of Rio de Janeiro.

\section{References}

[1] S.P. Arya, Micrometeorology and atmospheric boundary layer, Pure Apllied Geophys. 162 (2005) 1721-1745.

[2] T. Muneer, Solar Irradiation and Daylight Models, second ed., Elsevier, Amsterdam, 2004, p. 345

[3] E.B. Pereira, F.R. Martins, S.L. Abreu, S. Colle, Brazilian atlas for solar energy resource: Swera results, São José Dos. Campos INPE (2006) 60.

[4] S. Janjai, P. Pankaew, J. Laksanaboonson, A model for calculating hourly global solar radiation from satellite data in the tropics, Appl. Energy 86 (2009) $1450-1457$.

[5] T.S. Viana, R. Ruther, F.R. Martis, E.B. Pereira, Assessing the potential of concentrating solar photovoltaic generation in Brazil with satellite-derived direct normal irradiation, Sol. Energy 85 (2011) 486-495.

[6] J. Kanters, M. Wall, E. Kjellsson, The solar map as a knowledge base for solar energy use, Energy Procedia 48 (2014) 1597-1606.

[7] M.C. Rodríguez-Hidalgo, P.A. Rodríguez-Aumente, A. Lecuona, M. Legrand, R. Ventas, Domestic hot water consumption vs. solar thermal energy storage: the optimum size of the storage tank, Appl. Energy 97 (2012) 897-906.

[8] F.I. Woodward, J.E. Sheehy, Principles and Measurements in Environmental Biology, first ed., Butterworth \& Co, London, 1983, p. 263.

[9] Monteith JL, Unsworth M. Principles of Environmental Physics: Plants, Animals and the Atmosphere. fourth ed., Oxford: Elsevier; 401p.

[10] I. Supit, R.R. Van Kappel, A simple method to estimate global radiation, Sol Energy 63 (1998) 147-160.

[11] P. Redweik, C. Catita, M. Brito, Solar energy potential on roofs and facades in an urban landscape, Sol. Energy 97 (2013) 332-341.

[12] F.R. Martins, R. Rüther, E.B. Pereira, S.L. Abreu, Solar energy scenarios in Brazil. Part two: photovoltaics applications, Energy Police 36 (2008) 2865-2877.

[13] M.G. Pereira, C.F. Camacho, M.A.V. Freitas, N.F. Silva, The renewable energy market in Brazil: current status and potential, Renew. Sustain. Energy Rev. 16
(2012) 3786-3802

[14] D. Pottmaier, C.R. Melo, M.N. Sartor, S. Kuester, T.M. Amadio, C.A.H. Fernandes, D. Marinha, O.E. Alarcon, The Brazilian energy matrix: from a materials science and engineering perspective, Renew. Sustain. Energy Rev. 19 (2013) 678-691.

[15] R. Rüther, R. Zilles, Making the case for grid-connected photovoltaics in Brazil, Energy Police 39 (2011) 1027-1030.

[16] EPE, Balanço Energético Nacional 2015 - Ano Base 2014: Relatório Síntese, Empresa de Pesquisas Energéticas EPE, Rio de Janeiro, 2015, p. 62 (in portuguese).

[17] A.P. Oliveira, J.A. Machado, J.F. Escobedo, J. Soares, Diurnal evolution of solar irradiation at the surface in the city of São Paulo: Seasonal variation and modeling, Theor. Appl. Climatol. 71 (2002) 231-249.

[18] F.H. Assunção, J.F. Escobedo, A.P. Oliveira, Modelling frequency distributions of 5 minute-averaged solar radiation indexes using Beta probability functions, Theor. Appl. Climatol. 75 (2007) 213-224.

[19] J.L. Flores, H.A. Karam, E.P. Marques Filho, A.J. Pereira Filho, Estimation of atmospheric turbidity and surface radiative parameters using broadband clear sky solar irradiance models in Rio de Janeiro-Brasil, Theor. Appl. Climatol. (2015) 1-25 online.

[20] G. Codato, A.P. Oliveira, J. Soares, J.F. Escobedo, E.N. Gomes, A.D. Pai, Global and diffuse solar irradiances in urban and rural areas in southeast Brazil, Theor. Appl. Climatol. 93 (2008) 57-73.

[21] M.J. Ferreira, A.P. Oliveira, J. Soares, G. Codato, E.W. Bárbaro, J.F. Escobedo, Radiation balance at the surface in the City of São Paulo, Brazil. Diurnal and seasonal variations, Theor. Appl. Climatol. 107 (2012) 229-246.

[22] F.R. Martins, E.B. Pereira, S.L. Abreu, Satellite-derived solar resource maps for Brazil under SWERA project, Sol. Energy 81 (2007) 517-528.

[23] B.Y.H. Liu, R.C. Jordan, The interrelationship and characteristic distribution of direct, diffuse and total solar-radiation, Sol. Energy 4 (1960) 1-9.

[24] C.P. Jacovides, F.S. Tymviosa, V.D. Assimakopoulos, N.A. Kaltsounides, Comparative study of various correlations in estimating hourly diffuse fraction of global solar radiation, Renew. Energy 31 (2006) 2492-2504.

[25] J.L. Torres, M. De Blas, A. García, A. Francisco, Comparative study of various models in estimating hourly diffuse solar irradiance, Renew. Energy 35 (2010) 1325-1332.

[26] F. Lanini, Division of Global Radiation into Direct Radiation and Diffuse Radiation, Master's thesis, Faculty of Science, University of Bern, 2010, p. 122.

[27] D.G. Erbs, S.A. Klein, J.A. Duffie, Estimation of the diffuse-irradiation fraction for hourly, daily and monthly-average global irradiation, Sol. Energy 28 (1982) 293-302.

[28] D.T. Reindl, W.A. Beckman, J.A. Duffie, Diffuse fraction correlations, Sol. Energy 45 (1990) $1-7$

[29] A. Skartveit, J.A. Olseth, M.E. Tuft, An hourly diffuse fraction model with correction for variability and surface albedo, Sol. Energy 63 (1998) 173-183.

[30] B. Ridley, J. Boland, P. Lauret, Modelling of diffuse solar fraction with multiple predictors, Renew. Energy 35 (2010) 478-483.

[31] J. Boland, L.C. McArthur, M. Luther, Modelling the diffuse fraction of global solar radiation on a horizontal surface, Environmetrics 12 (2001) 103-116.

[32] J. Boland, B. Ridley, Models of diffuse solar fraction, in: V. Badescu (Ed.), Modelling Solar Radiation at the Earth's Surface, Springer-Verlag, Berlin, Heidelberg, 2008, pp. 193-219.

[33] A.P. Oliveira, A.J. Machado, J.F. Escobedo, J. Soares, Correlation models of diffuse solar-irradiation applied to the city of São Paulo, Brazil, Appl. Energy 71 (2002) 59-73.

[34] J. Soares, A.P. Oliveira, M.Z. Boznar, P. Mlakar, J.F. Escobedo, J. Machado, Modeling hourly diffuse solar radiation in the city of São Paulo using neural network technique, Appl. Energy 79 (2004) 201-214.

[35] C. Furlan, A.P. Oliveira, J. Soares, G. Codato, J.F. Escobedo, The role of clouds in improving the regression model for hourly values of diffuse solar radiation, Appl. Energy 92 (2012) 240-254.

[36] IBGE, Instituto Brasileiro de Geografia e Estatística, Portal Cidades@, 2014 http://www.cidades.ibge.gov.br/xtras/home.php?lang=_EN.

[37] A. Sherbinin, A. Schiller, A. Pulsipher, The vulnerability of global cities to climate hazards, Environ. Urbanization 19 (2007) 39-64.

[38] M. Zeri, J.F. Oliveira Júnior, G.B. Lyra, Spatio temporal analysis of particulate matter, sulfur dioxide and carbon monoxide concentrations over the city of Rio de Janeiro, Braz. Meteorol. Atmos. Phys. 113 (2011) 139-152.

[39] A.J. Lucena, O.C. Rotunno Filho, J.R.A. Franç, L.F. Peres, L.N.R. Xavier, Urban Climate and Clues of Heat Island Events in the Metropolitan Area of Rio de Janeiro, Theor. Appl. Climatol. 111 (2013) 497-511.

[40] A.P. Oliveira, J.A. Machado, J.F. Escobedo, J. Soares, New Shadow-Ring device for Measuring Diffuse Solar Irradiation at the Surface, J. Atmos. Ocean. Technol. 19 (2002) 698-708.

[41] M.C. Peel, B.L. Finlayson, T.A. McMahon, Updated world mao of the KöppenGeiger climate classification, Hydrol. Earth Syst. Sci. 11 (2007) 1633-1644.

[42] S.N. Figueroa, P. Satyamurty, P.L. Silva Dias, Simulations of the summer circulation over the South American region with an Eta coordinate model, J. Atmos. Sci. 52 (1995) 1573-1584.

[43] B. Liebmann, G.N. Kiladis, J.A. Marengo, T. Ambrizzi, J.D. Glick, Submonthly Convective Variability over South America and the South Atlantic Convergence Zone, J. Clim. 12 (1999) 1877-1891.

[44] R.D. Garreaud, M. Vuille, R. Compagnucci, J. Marengo, Present-day South American climate, Palaeogeogr. Palaeoclimatol. Palaeoecol. 281 (2009) 180-195. 
[45] J.A. Marengo, S.C. Chou, R.R. Torres, A. Giarolla, L.M. Alves, A. Lyra, climate change in central and South America: recent trends, future projections, and impacts on regional agriculture, Working Paper No. 73, CGIAR Res. Program Clim. Change Agric. Food Secur. (CCAFS) (2014) 91

[46] J. Hansen, M. Sato, R. Ruedy, G.A. Schmidt, K. Lo, Global Temperature in 2014 and 2015, Earth Institute of Columbia University, 2015. http://csas.ei. columbia.edu/2015/01/16/global-temperature-in-2014-and-2015/.

[47] D.J. Gaffen, R.J. Ross, Climatology and Trends of U.S. Surface Humidity and Temperature, J. Clim. 12 (1999) 811-828.

[48] P. Bacher, H. Madsen, B. Perers, H.A. Nielsen, A non-parametric method for correction of global radiation observations, Sol. Energy 88 (2013) 13-22.

[49] L. Vuilleumier, M. Hauser, C. Félix, F. Vignola, P. Blanc, A. Kazantzidis, B. Calpini, Accuracy of ground surface broadband shortwave radiation monitoring, J. Geophys. Res. Atmos. 119 (2014) 13838-13860.

[50] S. Younes, R. Claywell, T. Muneer, Quality control of solar radiation data: present status and proposed new approaches, Energy 30 (2005) 1533-1549.

[51] R. Perez, P. Ineichen, R. Seals, A. Zelenka, Making full use of the clearness index for parameterizing hourly insolation conditions, Sol. energy 45 (1990) $111-114$.

[52] C.A. Gueymard, Importance of atmospheric turbidity and associated uncertainties in solar radiation and luminous efficacy modelling, Energy 30 (2005) 1603-1621.

[53] J. Boland, J. Huang, B. Ridley, Decomposing global solar radiation into its direct and diffuse components, Renew. Sustain. Energy Rev. 28 (2013) 749-756.

[54] M. Journée, C. Bertrand, Quality control of solar radiation data within the RMIB solar measurements network, Sol. Energy 85 (2011) 72-86.

[55] M. Iqbal, An Introduction to Solar Irradiation, Academic Press, Toronto, 1983, p. 390.

[56] C. Fröhlich, J. Lean, The Sun's total irradiance: cycles, trends and related climate change uncertainties since 1976, Geophys. Res. Lett. 25 (1998) 4377-4380.

[57] F.J. Batlles, F.J. Olmo, L. Alados-Arboledas, On shadowband correction methods for diffuse irradiance measurements, Sol. Energy 54 (1995) 105-114.

[58] C. Gueymard, Critical analysis and performance assessment of clear sky solar irradiance models using theoretical and measured data, Sol. Energy 51 (1993) $121-138$.

[59] C.A. Boor, Practical Guide to Splines, in: J.E. Marsden, L. Sirovich (Eds.), Applied Mathematical Science vol. 27, Springer-Verlag, New York, 2001, p. 354.

[60] F.J. Newland, A study of solar radiation models for the coastal region of South China, Sol. Energy 43 (1989) 227-235.

[61] H.J. Motulski, A. Christopoulos, Fitting Models to Biological Data Using Linear and Nonlinear Regression. A Pratical Guide to Curve Fitting, GraphPad Software Inc., San Diego, CA, 2003, p. 351.

[62] K.P. Burnham, D.R. Anderson, Multimodel inference: understanding AIC and BIC in model selection, Sociol. Methods \& Res. 33 (2004) 261-304. 